\title{
Hydrogen sulphide inhalational toxicity at a petroleum refinery in Sri Lanka: a case series of seven survivors following an industrial accident and a brief review of medical literature
}

\author{
Mitrakrishnan Chrishan Shivanthan ${ }^{1 *}$, Harshani Perera', Saroj Jayasinghe ${ }^{1,2}$, Panduka Karunanayake ${ }^{1,2}$, \\ Thashi Chang ${ }^{1,2}$, Sujatha Ruwanpathirana ${ }^{1}$, Nilwala Jayasinghe ${ }^{1}$, Yamini De Silva ${ }^{1}$ and Dinushka Jayaweerabandara
}

\begin{abstract}
This case series details clinical observations in 7 survivors of accidental hydrogen sulphide inhalation toxicity at a petroleum refinery in Sri Lanka. One survivor developed status epilepticus and severe neurotoxicity whilst another survivor developed delayed respiratory failure; both patients required intensive care management. One victim manifested mild bronchospasms in the immediate post-exposure period and another developed mild perioral numbness 2 days following the exposure. A brief literature review explores the manifestations, pathophysiology and available modalities of treatment of hydrogen sulphide inhalation toxicity.
\end{abstract}

Background: Hydrogen sulphide $\left(\mathrm{H}_{2} \mathrm{~S}\right)$ is a highly toxic gas. Accidental deaths following $\mathrm{H}_{2} \mathrm{~S}$ exposure is a known hazard amongst petroleum workers exposed to by-products of refineries. Toxicity results mainly due to cellular respiratory poisoning which impairs oxidative phosphorylation. The heart, brain and the lungs are the organs most commonly affected in $\mathrm{H}_{2} \mathrm{~S}$ inhalational toxicity leading to varied clinical presentations.

Keywords: Hydrogen Sulfide/Sulphide, $\mathrm{H}_{2} \mathrm{~S}$, Petroleum, Inhalation, Toxicity, Industrial accident

\section{Case series presentation}

Workmen engaged in repair work at an oil refinery in Sri Lanka were accidentally exposed to toxic fumes following a leak in a pipeline in mid-November 2012.

Hydrogen sulphide is the primary established noxious effluent carried in the damaged pipes. Other toxic agents have never been identified during prior analysis of effluent gases by the chemical engineering department of the institution and therefore are either absent or of negligible levels. The victims were exposed to hydrogen sulphide fumes for a period of approximately 10 minutes before rescue was attempted. The concentration of hydrogen sulphide in the vicinity of the accident or levels each individual was exposed to were not measured.

The victims were immediately taken to hospital but two were declared dead on admission. This case series documents the clinical and laboratory observations in 7 of the workmen who survived toxic exposure to $\mathrm{H}_{2} \mathrm{~S}$

\footnotetext{
* Correspondence: mcs627@gmail.com

'National Hospital of Sri Lanka, Colombo, Sri Lanka

Full list of author information is available at the end of the article
}

inhalation. Blood hydrogen sulphide levels could not be measured in the victims as the test is not available in the health sector of Sri Lanka.

\section{Case 1}

A 36-y-old male admitted to the emergency treatment unit within 1 hour of $\mathrm{H}_{2} \mathrm{~S}$ exposure was found to be unconscious with cyanosis, labored-breathing, bronchospasms and generalized muscle twitching. He developed three genreralized tonic-clonic convulsions within a period of 30 minutes. His arterial blood oxygen saturation on pulse oximetry was $80 \%$ breathing air, while his blood pressure was $80 / 50 \mathrm{~mm} \mathrm{Hg}$. He was resuscitated with bag and mask ventilation with high flow oxygen and nebulized with salbutamol and ipratropium bromide. He developed frequent ventricular ectopics and runs of bradycardia associated with hypotension, but these responded to anti-arrhythmic drugs. Seizures were treated with parenteral benzodiazepines. Additionally, he was given a single dose of intravenous hydrocortisone $200 \mathrm{mg}$. Capillary plasma glucose was normal. The 
arterial blood gas analysis during ambu ventilation was found to be normal.

The specific antidote sodium nitrite was administered within 15 minutes of admission, which was 90 minutes post-exposure. Despite these measures, he developed recurrent seizures, deepening unconsciousness and decerebrate posturing. He was treated with parenteral barbiturates, intubated and artificially ventilated with $100 \%$ oxygen.

He was noted to have multiple neurofibromas on his body and his medical records confirmed a diagnosis of neurofibromatosis with a history of epilepsy since childhood. He had been seizure-free for almost 5 years following supervised withdrawal of phenytoin sodium in 2008. He had had decompressive-neurosurgery in 2008 for cervical radiculo-myelopathy secondary to neurofibromatosis. He was commenced on phenytoin sodium and sodium valproate via the nasogastric tube in view of recurrent decerebrate posturing. His pupils remained pin point and reacted sluggishly to light. The plantar reflexes were flexor. There were no focal neurological signs. His lungs remained clear except for a few scattered wheezes and he was in sinus rhythm.

By day 3 he had regained consciousness and was extubated uneventfully. However, he had marked truncal ataxia and a scanning dysarthria on recovery. These were associated with dysdiadochokinesia, dysmetria and intention tremor, but sans nystagmus. He also complained of a mild left-sided hearing impairment of recent onset.

Routine haematological and biochemical investigations including full blood count, liver function tests, renal profile and inflammatory markers did not demonstrate any abnormality.

An MRI of the brain done on day 5 failed to detect any structural abnormality to account for the cerebellar dysfunction and hearing loss. A pure tone audiogram done on day 14 was normal.

His anti-epileptic drugs were reduced to phenytoin monotherapy. His dysarthria and ataxia improved over the following two weeks. He was discharged 20 days after admission with residual mild-dysarthria and mildataxia of a modified Rankin scale of 2 . He continued to have retrograde amnesia of events preceding the occupational accident.

\section{Case 2}

A 46-y-old male exposed to hydrogen sulphide fumes while rescuing his colleagues presented on day 4 postexposure with worsening shortness of breath, dry cough and noisy breathing. On examination, he was mildly dyspnoeic and had scattered wheezes in both lung fields with no crepitations. His arterial blood oxygen saturation on pulse oximetry was $98 \%$. Cardiovascular examination was unremarkable.
He had pre-exisiting bronchial asthma, hypertension and diabetes mellitus. The asthma was controlled with prophylactic daily inhaled corticosteroids and intermittent inhaled salbutamol. He was a smoker (5 pack-years to date).

A baseline chest radiograph on admission was unremarkable. He had a neutrophil leukocytosis of $23 \times 10^{3} / \mathrm{ul}$. The other cell lines were normal.

$\mathrm{He}$ was administered oral steroids $(1 / \mathrm{mg} / \mathrm{kg})$, theophylline, co-amoxiclav and nebulized salbutamol and ipratropium bromide. However, over the next 3 days his condition deteriorated and he became very dyspnoeic. His oxygen saturation on air was $88 \%$ with an arterial oxygen tension of $60 \mathrm{mmHg}$; $\mathrm{PaCO} 2$ was $26 \mathrm{mmHg}$; and bicarbonate was normal. ECG did not show any abnormalities. Biochemical investigations apart for hypomagnesemia $(0.6 \mathrm{mmol} / \mathrm{l})$ were normal. A review chest radiograph did not show a cause for his acute respiratory decompensation. He was admitted to the intensive care unit and treated with high-flow oxygen, intravenous ceftriaxone, intravenous magnesium sulphate, oral potassium supplements and frequent nebulizations. However, his arterial oxygen saturation further reduced requiring non-invasive continuous positive airway pressure support with an $\mathrm{FiO}_{2}$ of $60 \%$. His arterial oxygen saturation improved to $97 \%$. He was then administered $1000 \mathrm{mg}$ of methylprednisolone intravenously per day on 3 consecutive days. On the following day, he developed $\mathrm{T}$ wave inversion in inferior and lateral leads of his ECG, but cardiac enzymes and echocardiogram remained normal. He gradually improved over the ensuing days and was weaned off the ventilator day 7 post-admission. A subsequent HRCT of the chest did not show any abnormality. He was discharged from hospital 5 days later, with a diagnosis of late chemical pneumonitis and hypoxic cardiac ischaemia following hydrogen sulphide inhalational toxicity.

\section{Case 3}

A 40-year-old male presented in the immediate postexposure period with bronchospasms without evidence of hypoxia. He was administered nebulized salbutamol and ipratropium bromide, and intravenous hydrocortisone. His haematological and biochemical tests, ECG, and chest radiograph were normal. His oxygen saturation remained stable. He was discharged 3 days postexposure without further sequelae.

\section{Case 4}

A previously well male developed peri-oral numbness on day 3 post-exposure. He had not had features of acute toxicity. General and systemic examinations were normal. Chvostek and Trousseau signs were both negative. Biochemical tests including serum ionized calcium, magnesium, routine haematological tests, chest radiograph 
and ECG were normal. He was discharged 2 days following admission.

\section{Case 5 to 7}

Three exposure victims did not develop any clinical or laboratory features of toxicity. They had inhaled only small amounts of the leaked $\mathrm{H}_{2} \mathrm{~S}$ fumes during the occupational accident.

\section{Discussion}

Hydrogen Sulphide $\left(\mathrm{H}_{2} \mathrm{~S}\right)$ is a highly toxic, colorless gas that is recognized by a pungent odour reminiscent of 'rotten eggs'. It is used in several industries and is a product of many industrial processes such as oil refining, mining and rayon manufacture [1]. $\mathrm{H}_{2} \mathrm{~S}$ originates mainly during breakdown of organic matter under anaerobic conditions. Following inhalation, $\mathrm{H}_{2} \mathrm{~S}$ dissociates into free sulphide and hydrogen ions in the blood circulation. Sulphide binds to many macromolecules, including cytochrome oxidase thereby preventing oxidative phosphorylation. This causes reversible inhibition of aerobic metabolism leading to cellular anoxia $[2,3]$.

Accidental deaths following accidental $\mathrm{H}_{2} \mathrm{~S}$ exposure is a known hazard amongst petroleum workers [4]. $\mathrm{H}_{2} \mathrm{~S}$ has also been implicated in deaths in farms following slurry or manure related accidents [5].

The development of seizures in case 1 is of considerable interest. It could be due to the seizure threshold being reached due to irritant effects of anoxia or due to effects of $\mathrm{H}_{2} \mathrm{~S}$ itself. $\mathrm{H}_{2} \mathrm{~S}$ has been known to characteristically cause sudden loss of consciousness which is colloquially termed 'knockdown' [3,6]. Coma is often associated with severe poisonings by $\mathrm{H}_{2} \mathrm{~S}$ [7]. Recent studies have shown that neurons have relatively high $\mathrm{H}_{2} \mathrm{~S}$ levels that act as messengers and therefore $\mathrm{H}_{2} \mathrm{~S}$ is a neuromodulator [8]. Animal studies indicate that this neuromodulation includes up-regulation and increased expression of gamma-aminobutyric acid $B$ receptor subunits $1(\mathrm{GABA}(\mathrm{B}) \mathrm{R} 1)$ and $2(\mathrm{GABA}(\mathrm{B}) \mathrm{R} 2)$ [9]. However, since GABA has inhibitory effects on neurons, one would not expect $\mathrm{H}_{2} \mathrm{~S}$ to reduce the seizure threshold [10]. Therefore our patient probably developed seizures as a consequence of the combination of hypoxic and histotoxic hypoxia in the background of a propensity for seizures, rather than a direct toxic effect of $\mathrm{H}_{2} \mathrm{~S}$.

Post-anoxic neurological sequelae have been reported [6]. Survivors have been reported to exhibit neurobehavioral effects following acute, non-fatal $\mathrm{H}_{2} \mathrm{~S}$ intoxication with proven reduction of cognitive capabilities, depressive symptoms and personality changes even though the results of neurological examination and neuroimaging techniques remained unremarkable [1]. A case report detailing the sequelae following $\mathrm{H}_{2} \mathrm{~S}$ exposure in a 27-year-old male with Glasgow Coma Score which improved from 3 to 15 over a 7 day period with hyperbaric oxygen therapy showed that though both CT and MRI of brain were unremarkable, PET scan 3 years later showed abnormally decreased metabolism bilaterally in the temporal, inferior parietal lobes, left thalamus and abnormal uptake in the striatum. Further cerebral perfusion studies showed bilaterally decreased flow in the putamen without cortical abnormalities. Neuropsychological and neurofunctional testing revealed microsmia, psychomotor slowing, extrapyramidal signs and deficits in memory and executive/planning functioning [11]. The primary effects of $\mathrm{H}_{2} \mathrm{~S}$ may be confounded by anoxia or head trauma [3]. Persistent vegetative state is also a described phenomenon [6]. Subclinical and clinical neuropsychiatric disorders have been documented to manifest in the long-term in cases with exposure without acute loss of consciousness [12]. A recent study carried out in mice however demonstrated that when first put into a suspended animation-like state by a 20-min pretreatment with $\mathrm{H}_{2} \mathrm{~S}$ followed by exposure to a hypoxic environment survival is prolonged with no apparent detrimental effects compared to mice which were not pretreated with $\mathrm{H}_{2} \mathrm{~S}$. Hence $\mathrm{H}_{2} \mathrm{~S}$ also has a propensity to ameliorate hypoxic damage following exposure [13] Studies have also demonstrated that $\mathrm{H}_{2} \mathrm{~S}$ can induce a hypometabolic, hibernation-like state in mammals when given in subtoxic concentrations which will reduce the demand for oxygen and minimize unavoidable hypoxiainduced injury such as ischemia/reperfusion injury during renal transplantation [14].

The features of central nervous system toxicity observed in the patient 1 overlaps with previously documented features and pathophysiology of neurotoxicity seen after hydrogen sulphide inhalation which are described above. New onset cerebellar dysfunction though unique to this patient could probably be explained by cytotoxic hypoxic injury to neurons. Despite the preexisting neurofibromatosis and past history of seizures controlled by antiepileptics the temporal relationship to hydrogen sulphide exposure clearly establishes a cause and effect link between the abnormality and the toxic agent. PET scanning was not performed on our patient due to financial constraints despite literature evidence of studies showing abnormalities on PET imaging which were undetectable on MRI and CT scanning. Early administration of antidote and ventilation with $100 \%$ oxygen is likely to have minimized the severity of hypoxic damage. Persistent retrograde amnesia could either a post traumatic event or more likely the result of hypoxic damage to neurons involved in the complex tasks of processing memories.

The delayed onset respiratory failure seen in patient 2 is probably explained by a reactive airway dysfunction syndrome for which he probably could have had a 
predisposition as a result of asthma and chronic smoking. The absence of radiological evidence does not disprove the entity as the pathology is one of airways rather than gas exchange interface or alveolar parenchyma. Response to steroids and ventilator support with high $\mathrm{FiO} 2$ with complete reversibility and the temporal relationship to the exposure in this instance establish the relationship between the phenomenon and the toxic agent. Hypomagnesemia is a new observation hitherto unreported following hydrogen sulphide inhalation and is worthwhile looking for in future cases. Late onset perioral numbness reported in one of the cases was not substantiated by other clinical features of hypocalcemia or biochemical investigations to suggest a disturbance of calcium or magnesium homeostasis.

Animal studies following $\mathrm{H}_{2} \mathrm{~S}$ poisoning have demonstrated respiratory and circulatory changes as early as 10-15 minutes with $100 \%$ involvement in $20-25$ minutes in anaesthetized cats with severe respiratory disturbances and abrupt decrease of mean systemic arterial pressure and decreased cardiac output [15]. Studies in rats have demonstrated morpho-functional alterations in the aero-hemic barrier and surfactant system of the lungs with resultant pulmonary oedema [16]. Acute respiratory failure caused by an acute pulmonary oedema with left ventricular systolic dysfunction as a possible cause of this cardiorespiratory complication has been purported in medical literature [7]. Exposure to higher concentrations increase the risk of pulmonary oedema [3]. A late onset reactive airways dysfunction syndrome (RADS) after exposure to a high level of toxic gases mainly hydrogen sulphide has been described in a previously non-atopic man which had manifested with moderate, partially reversible, airway obstruction and increased responsiveness [17]. Hemorrhagic bronchitis and pneumonitis have been demonstrated in postmortem studies and subacute lung injuries following long term exposure to hydrogen sulphide has also been postulated [18].

Hydrogen sulphide induced mucosal irritation may predominate at lower concentrations with a keratoconjunctivitis called 'gas eye' [3] Animal model studies using exfoliative cytology has yielded quantitative information of value in ocular irritation studies [19].

Blood sulphide levels are useful in the diagnosis of hydrogen sulphide toxicity and help to differentiate it from others with a similar presentation. Delta aminolaevulunic acid synthase and haem synthase levels are known to be decreased following exposure to hydrogen sulphide; however no correlate could be drawn to levels of blood sulphide in survivors [20].

Treatment following hydrogen sulphide toxicity is currently empirical, with a combination of nitrite and hyperbaric oxygen [3,21,22]. 4-dimethylaminophenol has also administered as an antidote, followed immediately by hyperbaric oxygen therapy [2].
The use of hyperbaric oxygen therapy (HBOT) for $\mathrm{H}_{2} \mathrm{~S}$ poisoning remains controversial, but has a similar underlying rationale to that in carbon monoxide poisoning. HBOT may play a useful role in improving oxygenation and acid-base status quickly and counteracting the decrement in oxygen carriage caused by methaemoglobinaemia due to antidote administration [2].

\section{Conclusions}

The authors recommend measures to improve safety of workers to minimize inhalational toxicity in situations with possible hydrogen sulphide exposure. Vigilant reporting of features of toxicity is needed in order to collate the features of toxicity of this noxious gas. Antidote use and hyperbaric oxygen therapy is beneficial in cases with severe exposure and significant toxicity and probably minimizes hypoxic tissue damage especially in the central nervous system.

\section{Consent}

Written informed consent was obtained from the patients for publication of this Case report and any accompanying images. A copy of the written consent is available for review by the Editor-in-Chief of this journal.

\section{Competing interests}

The authors declare that they have no competing interests.

\section{Authors' contributions}

All the authors were involved in the clinical management of the cases described, drafting of the manuscript, and literature survey. All authors read and approved the final manuscript.

\section{Author details}

${ }^{1}$ National Hospital of Sri Lanka, Colombo, Sri Lanka. ${ }^{2}$ Department of Clinical Medicine, Faculty of Medicine, University of Colombo, Colombo, Sri Lanka.

Received: 16 December 2012 Accepted: 8 April 2013

Published: 11 April 2013

\section{References}

1. Fenga C, Cacciola A, Micali E: Cognitive sequelae of acute hydrogen sulphide poisoning. A case report. La Medicina del lavoro 2002, 93(4):322-328.

2. Lindenmann J, Matzi V, Neuboeck N, Ratzenhofer-Komenda B, Maier A, Smolle-Juettner FM: Severe hydrogen sulphide poisoning treated with 4-dimethylaminophenol and hyperbaric oxygen. Diving and hyperbaric medicine: the journal of the South Pacific Underwater Medicine Society 2010, 40(4):213-217.

3. Guidotti TL: Hydrogen sulphide. Occup Med (Lond) 1996, 46(5):367-371.

4. Lewis RJ, Schnatter AR, Drummond I, Murray N, Thompson FS, Katz AM, Jorgensen G, Nicolich MJ, Dahlman D, Theriault G: Mortality and cancer morbidity in a cohort of Canadian petroleum workers. Occup Environ Med 2003, 60(12):918-928.

5. Hagley SR, South DL: Fatal inhalation of liquid manure gas. The Medical journal of Australia 1983, 2(9):459-460

6. Sanz-Gallen P, Nogue S, Palomar M, Rodriguez M, Marti MJ, Munne P: Acute poisoning caused by hydrogen sulphide: clinical features of 3 cases. An Med Interna 1994, 11(8):392-394.

7. Chaari A, Bahloul M, Chelly H, Sahnoun M, Bouaziz M: Neurological and heart failure following an accidental intoxication by hydrogen sulphide: a case report. Ann Fr Anesth Reanim 2010, 29(4):304-307.

8. Kimura H: Hydrogen sulfide as a neuromodulator. Mol Neurobiol 2002, 26(1):13-19. 
9. Han Y, Qin J, Chang X, Yang Z, Bu D, Du J: Modulating effect of hydrogen sulfide on gamma-aminobutyric acid $B$ receptor in recurrent febrile seizures in rats. Neurosci Res 2005, 53(2):216-219.

10. Bettler B, Kaupmann K, Mosbacher J, Gassmann M: Molecular structure and physiological functions of GABA(B) receptors. Physiol Rev 2004, 84(3):835-867.

11. Schneider JS, Tobe EH, Mozley PD Jr, Barniskis L, Lidsky TI: Persistent cognitive and motor deficits following acute hydrogen sulphide poisoning. Occup Med (Lond) 1998, 48(4):255-260.

12. Hirsch AR: Hydrogen sulfide exposure without loss of consciousness: chronic effects in four cases. Toxicol Ind Health 2002, 18(2):51-61.

13. Blackstone $E$, Roth MB: Suspended animation-like state protects mice from lethal hypoxia. Shock 2007, 27(4):370-372.

14. Bos EM, Leuvenink HG, Snijder PM, Kloosterhuis NJ, Hillebrands JL, Leemans JC, Florquin S, van Goor H: Hydrogen sulfide-induced hypometabolism prevents renal ischemia/reperfusion injury. J Am Soc Nephrol 2009, 20(9):1901-1905.

15. Trizno NN, Velikanov EB, Tarakanov IA, Safonov VA: Changes in respiration and blood circulation during the inhalation of air mixtures with lethal and sublethal concentrations of hydrogen sulfide-containing natural gas. Biull Eksp Biol Med 1993, 116(7):25-29.

16. Seredenko MM, Rozova EV, Velikanov EB, Trizno NN: The morphofunctional characteristics of the pulmonary air-blood barrier in rats breathing gas mixtures with a high content of hydrogen sulfide. Morfologiia 1992, 102(5):120-129.

17. Cormier Y, Coll B, Laviolette M, Boulet LP: Reactive airways dysfunction syndrome (RADS) following exposure to toxic gases of a swine confinement building. The European respiratory journal: official journal of the European Society for Clinical Respiratory Physiology 1996, 9(5):1090-1091.

18. Parra O, Monso E, Gallego M, Morera J: Inhalation of hydrogen sulphide: a case of subacute manifestations and long term sequelae. $\mathrm{Br} J$ Ind Med 1991, 48(4):286-287.

19. Lefebvre M, Yee D, Fritz D, Prior MG: Objective measures of ocular irritation as a consequence of hydrogen sulphide exposure. Vet Hum Toxicol 1991, 33(6):564-566.

20. Jappinen $P$, Tenhunen R: Hydrogen sulphide poisoning: blood sulphide concentration and changes in haem metabolism. Br J Ind Med 1990, 47(4):283-285.

21. Smith RP: Nitrite treatment for hydrogen sulfide poisoning. Ann Intern Med 1981, 95(6):782.

22. Ravizza AG, Carugo D, Cerchiari EL, Cantadore R, Bianchi GE: The treatment of hydrogen sulfide intoxication: oxygen versus nitrites. Vet Hum Toxicol 1982, 24(4):241-242.

doi:10.1186/1745-6673-8-9

Cite this article as: Shivanthan et al:: Hydrogen sulphide inhalational toxicity at a petroleum refinery in Sri Lanka: a case series of seven survivors following an industrial accident and a brief review of medical literature. Journal of Occupational Medicine and Toxicology 2013 8:9.

\section{Submit your next manuscript to BioMed Central and take full advantage of:}

- Convenient online submission

- Thorough peer review

- No space constraints or color figure charges

- Immediate publication on acceptance

- Inclusion in PubMed, CAS, Scopus and Google Scholar

- Research which is freely available for redistribution 